\title{
Pengembangan Sistem Klasifikasi Tipe Kepribadian Siswa Secara Psikologis dengan Algoritma Decision Tree $\mathrm{C.45}$
}

\author{
Rini Nuraini ${ }^{1 *}$, Rosyid Ridlo Al Hakim², Tuti Lisnawati ${ }^{3}$, Wieke Tsanya Fariati ${ }^{4}$ \\ ${ }^{1}$ Informatika, Universitas Nasional, Jakarta Selatan, Indonesia \\ ${ }^{2}$ Teknik Elektro, Universitas Global Jakarta, Depok, Indonesia \\ ${ }^{3}$ Manajemen Informatika, AMIK Citra Buana Indonesia, Sukabumi, Indonesia \\ ${ }^{4}$ Komputerisasi Akuntansi, AMIK Citra Buana Indonesia, Sukabumi, Indonesia \\ Email: 1," rini.nuraini@ civitas.unas.ac.id, ${ }^{2}$ rosyidridlo@ student.jgu.ac.id, ${ }^{3}$ tutilisnawati448@gmail.com, ${ }^{4}$ werari22@gmail.com \\ Email Penulis Korespondensi: rini.nuraini@civitas.unas.ac.id \\ Submitted: 16/12/2021; Accepted: 26/12/2021; Published: 31/12/2021
}

\begin{abstract}
Abstrak-Dalam dunia pendidikan mengetahui tipe kepribadian siswa adalah suatau hal yang sangat penting. Hal ini dikarenakan kepribadian sesorang berpengaruh dalam kegiatan belajarnya dan bagaimana dia mencerna serta menangkap materi yang disampaikan oleh guru. Untuk itu mengetahui klasifikasi kepribadian siswa perlu untuk diidentifikasi agar guru atau siswa itu sendiri dapat mengoptimalkan perubahan diri ke arah yang lebih baik dan positif. Penelitian ini bertujuan untuk mengembangkan sistem klasifikasi tipe kepribadian siswa secara psikologi dengan menggunakan algoritma pohon keputusan C.45. Tipe kepribadian yang digunakan sebagai kelas dalam klasifikasi yaitu berdasarkan psikologi, diantaranya: Sanguinis, Plegmatis, Koleris dan Melankolis. Pada penelitian ini akan dilakukan pengembangan sistem berbasis web, agar mudah digunakan untuk guru dan siswa untuk mengenali kepribadian dari siswa tersebut. Untuk mengetahui kepribadian siswa secara psikologis, siswa menjawab soal di sistem, kemudian sistem akan mengklasifikasikan berdasarkan jawaban dari siswa tersebut. Algoritma pohon keputusan C.45 berfungsi untuk menemukan pengetahuan atau pola-pola kesamaan karakteristik dalam suatu kelompok atau kelas tertentu. Dari hasi pengunjian mendapatkan nilai pecision sebesar $90 \%$, recall sebesar $85 \%$ dan accuracy sebesar $88 \%$. Ini menunjukkan bahwa algoritma pohon keputusan C.45 dapat melakukan klasifikasi tipe kepribadian dengan baik.
\end{abstract}

Kata Kunci: C.45; Kepribadian; Klasifikasi; Pengembangan Sistem; Pohon Keputusan

\begin{abstract}
In the world of education knowing the personality type of students is very important. This is because a person's personality is influential in his learning activities and how he digests and captures the material presented by the teacher. For this reason, knowing the classification of students' personalities needs to be identified so that teachers or students themselves can optimize self-change in a better and positive direction. This study aims to develop a psychological classification system for student personality types using the C.45 decision tree algorithm. The personality type used as a class in the classification is based on psychology, including: Sanguine, Phlegmatic, Choleric and Melancholic. In this study, a web-based system was developed, so that it is easy to use for teachers and students to recognize the personality of these students. To determine the personality of students psychologically, students answer questions in the system, then the system will classify based on the answers from these students. The C.45 decision tree algorithm serves to find knowledge or patterns of characteristic similarity in a particular group or class. From the test results, the pecision value is $90 \%$, the recall is $85 \%$ and the accuracy is $88 \%$. This shows that the C.45 decision tree algorithm can perform personality type classification well.
\end{abstract}

Keywords: C.45; Personality; Classification; System Development; Decision Tree

\section{PENDAHULUAN}

Berkembangnya dunia pendidikan saat ini, menuntut guru harus mampu mendidik dengan baik dan mampu menghasilkan siswa yang berkompeten. Pembelajaran bermutu lahir dari sistem pembelajaran yang sesuai dengan kebutuhan dan potensi yang dimiliki oleh siswa. Setiap siswa memiliki karakter berbeda-beda, maka teknik pembelajaran yang dilakukan oleh guru untuk menyampaikan pengetahuan juga harus menyesuaikan karakteristik daei siswa agar pengetahuan dapat diserap dengan baik. Dari mengetahui karakter siswa maka akan dapat menggali potensi dan kemampuan yang dimiliki sehingga dapat dikembangkan kemampuan yang terpendam pada dirinya dan prestasi belajarnya [1]. Karater dari siswa ini biasanya disebut dengan kepribadian. Kepribadian dapat diartikan sebagai keseluruhan cara seorang dalam melakuka tindakan dan interaksi dengan orang lain [2]. Kepribadian adalah dinamika dari psikologi seseorang berupa pola-pola tingkah laku yang spesifik dalam menghadapi sesuatu [3]. Kepribadian merupakan kesan yang paling menonjol yang di tunjukkan oleh seseorang terhadap orang lain. Kepribadian juga merupakan karakteristik atau cara bertingkah laku yang menentukan penyesuaian diri yang khas terhadap lingkungan [4]. Dengan bertingkah laku yang baik, maka akan membentuk kepribadian yang baik pula. Setiap orang mempunyai memiliki dalam berperilaku dalam kehidupan sehari-hari. Tipe kepribadian manusia berdasarkan psikologi umumnya terdiri dari empat tipe. Keempat tipe tersebut masuk dalam teori proto-psikologis, diantaranya: Sanguinis, Plegmatis, Koleris dan Melankolis. Dalam berinteraksi dengan orang lain yang ada di lingkungannya, seseorang akan memiliki tipe kepribadian masing-masing untuk beradaptasi atau menyesuaikan terhadap lingkungan. Hal ini tidak terkecuali bagi siswa, kepribadian sangat berpengaruh dalam kegiatan belajarnya dan bagaimana dia mencerna serta menangkap materi yang disampaikan oleh guru. Untuk itu sesuatu yang penting untuk diketahui tipe kepribadian siswa, agar guru atau siswa itu sendiri agar mudah mengoptimalkan perubahan diri ke arah yang lebih baik dan positif. Maka, dibutuhkan sebuah sistem yang dapat mengklasifikasikan tipe kepribadian siswa secara psikologis, agar dapat diketahui potensi dari siswa tersebut. 
Data mining merupakan proses memperoleh pengetahuan atau pola-pola tertentu dari kumpulan data [5]. Tujuan data mining diantaranya: klasifikasi, klasterisasi, menemukan pola asosiasi hingga melakukan peramalan [6]. Klasifikasi dalam data mining merupakan proses untuk menemukan definisi kesamaan karakteristik dalam suatu kelompok atau kelas (class) tertentu [7]. Dalam klasifikasi pengelompokan data dilakukan berdasarkan kelas label atau target [8][9]. Salah satu metode yang populer yang digunakan dalam klasifikasi pada data mining adalah algoritma C.45. Algoritma C4.5 merupakan algoritma yang digunakan untuk membentuk pohon keputusan (decision tree). Pohon keputusan adalah model prediksi melalui struktur pohon atau hirarki dengan melakukan perubahan pada data kedalam pohon keputusan dan aturan-aturan keputusan [10]. Pohon keputusan bertujuan agar dapat mengekspolari data, menggali informasi hubungan yang tersembunyi antara sejumlah calon variabel input dengan sebuah variabel target [11]. Pohon keputusan digunakan sebagai prosedur penalaran untuk mendapatkan jawaban dari masalah yang sebelumnya kompleks kemudian diubah menjadi lebih sederhana. Algoritma C4.5 memiliki kelebihan yaitu menghasilkan pohon keputusan yang mudah diinterprestasikan, memiliki tingkat akurasi yang dapat diterima, efisien dalam menyelesaikan permasalaha dengan atribut diskret dan numerik [12]. Dalam mengkonstruksi pohon, algoritma C4.5 melalui identifikasi dari seluruh sampel data training dari kumpulan data dan memuatnya ke memori. Beberapa penelitian menggunakan algoritma C.45 menunjukkan hasil dan akurasi yang baik. Penelitian sebelumnya mengenai penerapan algoritma C4.5 pada klasifikasi penyakit disk hernia dan spondylolisthesis [13]. Pada penelitian ini brdasarkan pengujian akurasi didapatkan nilai akurasi sebesar $89 \%$ dan rata-rata lama waktu yang dibutuhkan untuk melakukan klasifikasi adalah 0,00912297 detik. Penelitian selanjutnya tentang implementasi metode C.45 dalam klasifikasi tenaga marketing [14]. Pada penelitian ini metode yang diusulkan mampu menghasilkan akurasi sebesar 91,10\% dan evaluasi menggunakan ROC curve model yang diusulkan menghasilkan nilai AUC sebesar 0,921. Penelitian lainnya yaitu tentang klasifikasi tingkat kelulusan mahasiswa dengan pohon keputusan C.45 [15]. Berdasarkan hasil evaluasi dengan membandingkan keputusan asli dengan keputusan yang didapatkan dari metode yang diusulkan memperoleh nilai akurasi sebesar $94 \%$.

Tujuan dari penelitian ini adalah mengembangkan sistem klasifikasi tipe kepribadian siswa secara psikologi dengan menggunakan algoritma pohon keputusan C.45. Tipe kepribadian yang digunakan sebagai kelas dalam klasifikasi yaitu berdasarkan psikologi, diantaranya: Sanguinis, Plegmatis, Koleris dan Melankolis. Pada penelitian ini akan dikembangkan sistem berbasis web, agar mudah digunakan untuk guru dan siswa untuk mengenali kepribadian dari siswa tersebut. Untuk mengetahui kepribadian siswa secara psikologis, siswa akan menjawab soal di sistem, kemudian sistem akan mengklasifikasikan berdasarkan jawaban dari siswa tersebut. Algoritma pohon keputusan C.45 berfungsi untuk menemukan pengetahuan atau pola-pola kesamaan karakteristik dalam suatu kelompok atau kelas tertentu.

\section{METODOLOGI PENELITIAN}

\subsection{Tahapan Penelitian}

Untuk melakukan penelitian maka dibutuhkan perencanaan dan langkah-langkah yang terstuktur agar penelitian dapat berjalan dengan baik. Tahapan penelitian yang dilakukan dapat dilihat pada Gambar 1 berikut ini.

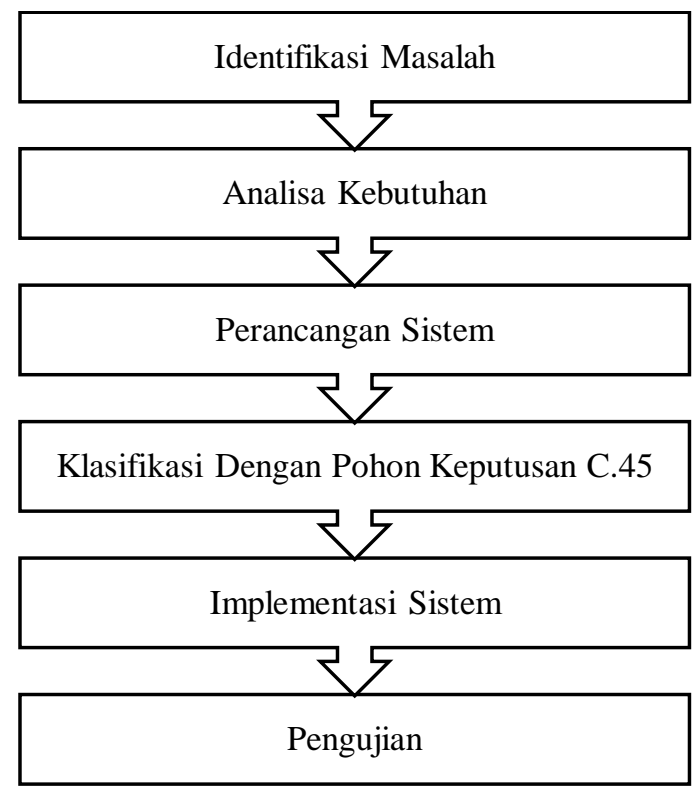

Gambar 1. Tahapan Penelitian 


\subsubsection{Identifikasi Masalah}

Kegiatan ini dimulai dengan mengumpulkan data melalui wawancara dengan tujuan mendengarkan pengguna, hal itu bermanfaat untuk mengetahui informasi apa saja permasalah yang akan diselesaikan [16]. Permasalahan utama pada penelitian ini adalah bagaimana membangun sistem yang dapat mengklasifikasikan kepirbadian siswa sehingga guru dan siswa itu sendiri dapat mengetahui kepribadian siswa.

\subsubsection{Analisa Kebutuhan}

Analisa kebutuahn luaran berupa software requirement yang berisi kebutuhan-kebutuhan fungsional yang dibutuhan oleh pengguna. Kebutuhan fungsional diperlukan untuk mengetahui proses apa saja yang dapat dilakukan oleh sistem, serta siapa saja yang dapat menggunakan sistem yang dibangun [17][18]. Berikut adalah kebutuhan fungsional dari sistem yang akan dikembangkan:

a. Admin

1. Admin dapat login kedalam sistem

2. Admin dapat mengelola data siswa

3. Admin dapat mengelola data soal

4. Admin dapat menginport data jawaban siswa dari excel

5. Admin mengatur rule pohon keputusan

6. Admin dapat melihat hasil kualifikasi

b. User

1. User dapat mengisi soal dan menjawab pertanyaan tes kepribadian

2. User dapat melihat hasil klasifikasi

\subsection{Perancangan Sistem}

Perancangan sistem melibatkan identifikasi dan deskripsi abstraksi sistem perangkat lunak yang mendasar dan hubungan-hubungannya [19]. Pada tahap perancangan, fokus kegiatan adalah merancang sistem dan alat untuk merancang pada tahap ini menggunakan use case diagram. Use case diagram mendeskripsikan sebuah interaksi antara satu atau lebih aktor dengan sistem informasi yang akan dibuat [20].

\subsection{Klasifikasi Dengan Pohon Keputusan C.45}

Algoritma pohon keputusan C4.5 merupakan model prediktif dalam menggunakan struktural pohon atau struktural hirarki [14]. Salah satu kinerja dari Algoritma C4.5 yaitu mengubah suatu data menjadi sebuah keputusan dalam bentuk pohon dengan aturan-aturan tertentu [21]. Kelebihan dalammenggunakan pohon keputusan yaitu prosesnya dalam menentukan keputusan yang kompleks dapat didekomposisi menjadi proses yang lebih sederhana [22]. Algoritma C4.5 juga memiliki kemampuan data mining dan kemampuan untuk menemukan hubungan tersembunyi antara sekumpulan variabel input yang mungkin dan variabel target [15]. Pada penelitian ini, algoritma C.45 akan mengklasifikasikan tipe kepribadian siswa berdasarkan jawaban yang ada pada soal tes kepribadian. Algoritma C.45 akan membangun pohon keputusan dari aturan-aturan yang ada berdasarkan data isian jawaban dari siswa. Untuk mengimplementasikan algoritma C.45 dilakukan perhitungan nilai entropy dan nilai gain. Enttorpy merupakan nilai informasi yang menyatakan ukuran ketidakpastian dari attribut dari suatu kumpulan obyek data [23]. Untuk menghitung entropy dapat melalui formula berikut ini:

$$
\operatorname{Entropy}(S)=\sum_{i=0}^{n}-p i * \log _{2} p i
$$

Dimana $S$ adalah himpunan kasus, n adalah jumlah partisi dari $S$, dan pi adalah probabilitas kasus dalam partisi ke-i.

Sedangkan gain adalah adalah ukuran efektifitas suatu atribut dalam mengklasifikasikan data yang digunakan agar dapat menentukan urutan atribut [24]. Untuk menghitung gain dapat melalui persamaan berikut ini:

$$
\operatorname{Gain}(S, A)=\operatorname{Entropy}(S)-\sum_{i=0}^{n} \frac{|S i|}{|S|} * \operatorname{Entropy}(S i)
$$

Dimana $A$ adalah himpunan penentu $|S i|$ adalah jumlah kasus pada partisi ke-i, dan $|S|$ adalah jumlah kasus dalam $S$.

\subsubsection{Implementasi Sistem}

Pada tahap ini dilakukan impelementasi melalu pengkodean berdasarkan dari perancangan dan analisa yang telah dilakukan sebelumnya. Pengkodean merupakan tahapan dimana rancangan yang telah dibuat kemudian diimplementasikan kedalam bentuk bahasa pemrograman yang dapat dikenali oleh komputer [25]. Pada penelitian ini, pengkodean dilakukan dengan menggunakan bahasa pemrograman PHP dengan compailer Sublime Text 3 dan database MySQL.

\subsubsection{Pengujian}

Untuk pengujian pada penelitian ini menggunakan confusion matrix, di mana akan dihitung nilai precision, recall, dan accuracy. Confusion matrix terdiri dari true positive, false positive, true negative dan false negative untuk menghitung presisi, recall dan akurasi [26]. Precision adalah tingkat ketepatan antara informasi yang diminta oleh 
pengguna dengan jawaban yang diberikan oleh sistem. Sedangkan recall adalah tingkat keberhasilan sistem dalam menemukan kembali sebuah informasi. Sedangkan Accuracy didefinisikan sebagai tingkat kedekatan antara nilai prediksi dengan nilai aktual. Untuk menghitung precision, recall dan accuracy dapat menggunakan persamaan berikut:

$$
\begin{aligned}
& \text { Precision }=\frac{T P}{T P+F P} \\
& \text { Recall }=\frac{T P}{T P+F N} \\
& \text { Accuracy }=\frac{T P+T N}{T P+T N+F P+F N}
\end{aligned}
$$

Dimana TP adalah true positive yang didapatkan dari jumlah data positif yang diprediksi benar. TN adalah true negative didapatkan dari jumlah data negatif yang diprediksi benar. FP adalah false positive didapatkan dari jumlah data negatif namun diprediksi sebagai data positif. Sedangkan FN adalah false negative yang diadapatkan dari jumlah data positif namun diprediksi sebagai data negatif.

\section{HASIL DAN PEMBAHASAN}

Untuk memulai mengembangkan sistem klasifikasi kepribadian siwa sicara psikologi langkah pertama adalah identifikasi masalah, agar dapat mendapatkan kebutuhan. Kebutuhan tersebut yang nantinya menjadi fungsional sistem. Dari analisa kebutuhan kemudian sistem dirancang. Pada penelitian ini sistem dirancang menggunakan use case diagram. Gambar 2 berikut ini adalah use case diagram dari sistem yang akan dikembangkan.

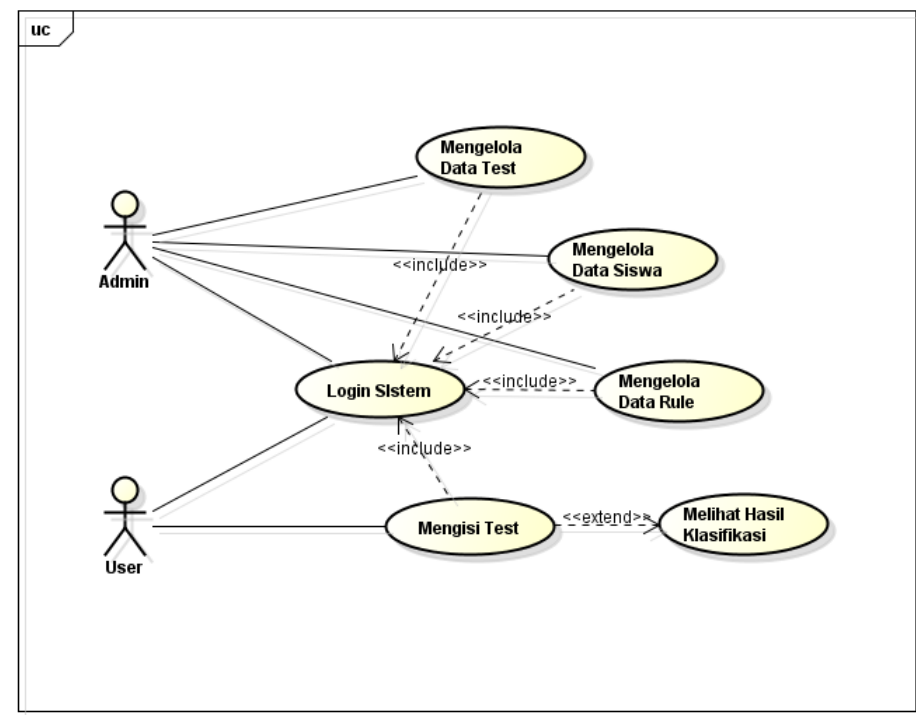

Gambar 2. Use Case Diagram Sistem Klasifikasi Tipe Kepribadian Secara Psikologis

Dari use case diagram pada Gambar 2, terdapat dua pengguna yaitu admin dan user. Admin dapat diperankan oleh guru, dimana admin dapat login sistem, mengelola dataset, mengelola data siswa dan mengelola rule. Sedangkan user atau siswa dapat login sistem, mengisi test dan melihat hasil klasifikasi.

Dalam mengembangkan sistem klasifikasi kepribadian siswa secara psikologi metode klasifikasi yang digunakan adalah algoritma C.45, dimana akan dilakukan membagi kelas-kelas yang terdapat dalam data yang digambarkan sebagai pohon keputusan.. Fungsi dari metode prediksi adalah untuk menentukan nilai yang hilang dari atribut target, dan memberikan prediksi dan penjelasan untuk prediksi tersebut. Nilai atribut hanya dapat diproduksi jika atribut target memiliki nilai yang perlu dicari. Pohon keputusan berfungsi untuk melakukan klasifikasi nilai dari satu kolom berdasarkan nilai dari kolom lainnya. Cara kerja klasifikasi pohon keputusan adalah dengan mengenal motif atau dengan fungsi dalam memisahkan kelas data satu dengan lainnya. Penerapan model dilakukan setelah mendapatkan model dari test klasifikasi berupa pertanyaan-pertanyaan tes kepribadian setelah itu diproses melalu algortima C.45 dan hasil akan didapatkan setelah pertanyaan-pertanyaan tersebut terisi. Proses klasifikasi menggunakan algoritma C.45 digambarkan pada flowchart berikut ini: 


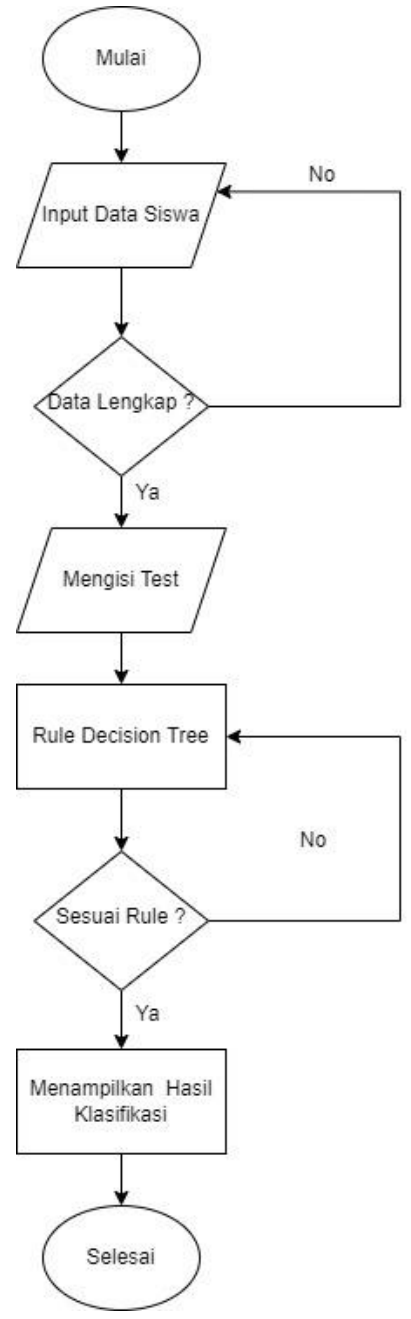

Gambar 3. Flowchart Cara Kerja Sistem

Pada Gambar 3, proses diawali dari siswa melakukan input data, jikat data diisi dengan lengkap maka siswa dapat melanjutkan untuk mengisi pertanyaa pada test kepribadian. Jawaban dari siswa tersebut selanjtunya akan dimasukkan kedalam rule decision tree. Rule atau aturan tersebut didapatkan dari perhitung entropy dan gain sehingga mendapatkan rule yang berbentuk pohon. Setelah jawaban dimasukan kedalam rule decision tree maka dilakukan klasifikasi kepribadian yang telah ditentukan sebelumnya. Berikut adalah beberapa contoh rule yang terbentuk dari algoritma C.45.

a. IF (jawaban_a $<=10$ ) AND (jawaban_c $<=10)$ AND (jawaban_b $<=10$ ) THEN Label = Plegmatis

b. IF (jawaban_a $<=10)$ AND (jawaban_c $<=10)$ AND (jawaban_b $>10)$ AND (jawaban_d $<=10)$ THEN Label = Koleris

c. IF (jawaban_a $<=10$ ) AND (jawaban_c $<=10)$ AND (jawaban_b>10) AND (jawaban_d $>10)$ AND (usia='14') THEN Label $=$ Koleris

d. IF (jawaban_a $<=10$ ) AND (jawaban_c $<=10)$ AND (jawaban_b $>10)$ AND (jawaban_d $>10)$ AND (usia='13' OR usia='15') AND (usia='13') AND (jenis_kelamin='L') THEN Label = Koleris

e. IF (jawaban_a $<=10$ ) AND (jawaban_c $<=10)$ AND (jawaban_b $>10)$ AND (jawaban_d $>10)$ AND (usia='13' OR usia='15') AND (usia='13') AND (jenis_kelamin='P') THEN Label = Koleris

f. IF (jawaban_a $<=10$ ) AND (jawaban_c $<=10$ ) AND (jawaban_b $>10)$ AND (jawaban_d $>10)$ AND (usia='13' OR usia='15') AND (usia='15') THEN Label = Plegmatis

g. IF (jawaban_a $<=10$ ) AND (jawaban_c $>10)$ AND (jawaban_d $<=10$ ) THEN Label = Melankolis

h. IF (jawaban_a $<=10$ ) AND (jawaban_c $>10)$ AND (jawaban_d $>10)$ AND (jenis_kelamin='L') THEN Label = Plegmatis

i. IF (jawaban_a<=10) AND (jawaban_c $>10)$ AND (jawaban_d $>10$ ) AND (jenis_kelamin='P') AND (usia='14') THEN Label $=$ Plegmatis

j. IF (jawaban_a $<=10$ ) AND (jawaban_c $>10)$ AND (jawaban_d $>10)$ AND (jenis_kelamin='P') AND (usia='13' OR usia='15') AND (usia='13') AND (sekolah='Negeri') AND (jawaban_a<=5) THEN Label = Plegmatis 
Building of Informatics, Technology and Science (BITS)

Volume 3, No 3, December 2021, Page 220-227

ISSN 2684-8910 (media cetak)

ISSN 2685-3310 (media online)

DOI 10.47065/bits.v3i3.1045

Setelah dilakukan analisa dan perancangan, selanjutnya adalah implementasi sistem. Agar guru dan siswa dapat menggunakan aplikasi dengan mudah maka aplikasi dibuat dalam bentuk GUI berbasis web. Pada penelitian ini, pengkodean dilakukan dengan menggunakan bahasa pemrograman PHP dengan compailer Sublime Text 3 dan database MySQL. Terdapat dua pengguna pada sistem klasifikasi kepribadian secara psikologi, yaitu admin dan user. Sebelum memulai klasifikasi kepribadian, admin dalam hal ini adalah guru, menginputkan data siswa melalui form data siswa sekaligus membuat user name siswa yang digunakan siswa untuk login kedalam sistem. Setelah menginputkan data siswa admin dapat mengelola pertanyaan untuk tes kepribadian. Data soal dapat diimport melalui file excel, sehingga guru dapat langsung memasukkan file excel tersebut. Setelah data soal diinputkan, selanjutnya admin dapat mengelola rule yang selanjutnya digunakan sebagai pohon keputusan untuk mengklasifikasikan kepribadian siswa. Aturan didapatkan dari hasil mining dengan menggunakan metode C.45. Tampilan pohon keputusan dapat dilihat pada gambar 4 berikut ini.

\section{Pohon Keputusan}

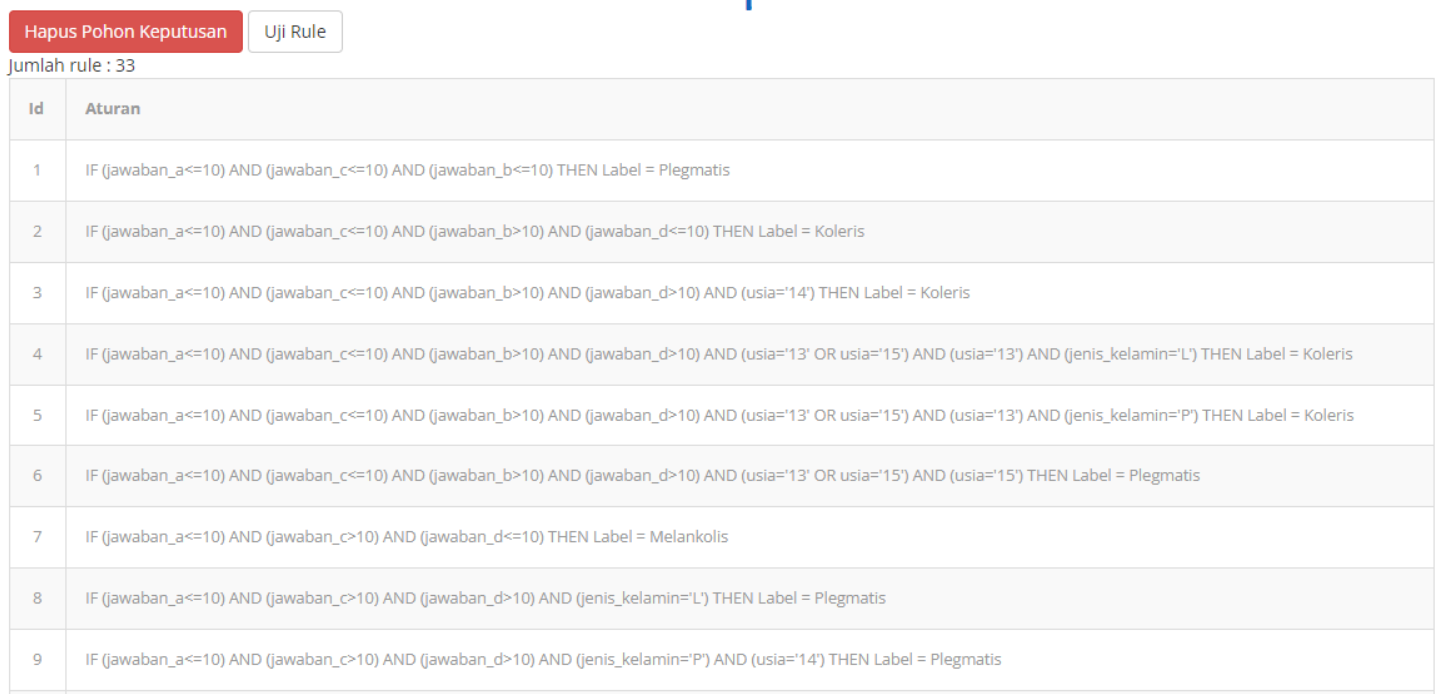

Gambar 4. Tampilan Mengelola Pohon Keputusan

Sedangkan untuk siswa, dapat melakukan test apabila sudah diinputkan datanya oleh admin. Admin akan memberikan username untuk siswa masuk kedalam sistem. Kemudian siswa dapat mengisi soal test yang telah disusun berdasarkan buku proto-psikologi seperti pada Gambar 5 berikut ini.

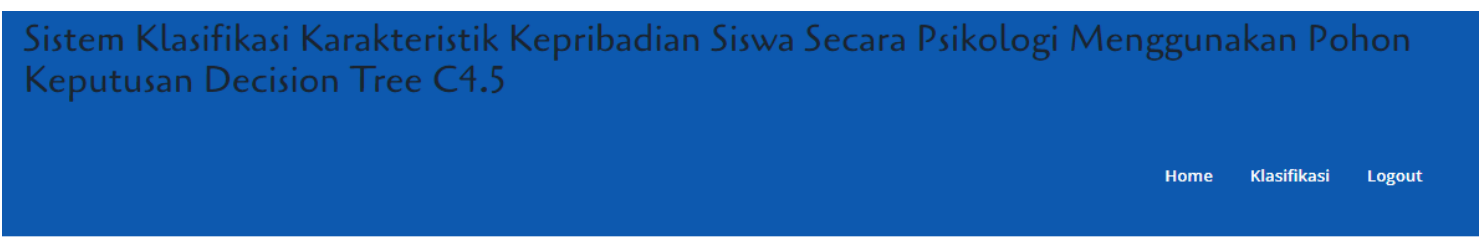

\section{Test Kepribadian Secara Psikologi}

No. 1

O Penuh kehidupan, sering menggunakan isyarat tangan, lengan, dan wajah secara hidup.(Animated)

O Orang yang mau melakukan sesuatu hal yang baru dan berani bertekad untuk me-nguasainya.(Adventurous)

Suka menyelidiki bagian - bagian yang logis. (Analitical)

Mudah menyesuaikan diri dan senang dalam setiap situasi. (Adaptable)

No. 2

Penuh kesenangan dan selera humor yang baik. (Playful)

Meyakinkan se-seorang dengan logika dan fakta, bukan dengan pesona / kekuasaan. (Persuasive)

Melakukan sesuatu sampai selesai sebelum memulai yang lain. (Persistent)

Tampak tidak ter-ganggu dan tenang serta menghindari setiap bentuk ke-kacauan. (Peaceful)

No. 3

O Orang yang memandang bersama orang lain sebagai kesempatan untuk bersikap manis dan menghibur, bukannya sebagai tantangan / kesempatan bisnis. (Sociable) Orang vang vakin dengan caranva cendiri (ctrong-willed)

Gambar 5. Tampilan Siswa Mengisi Soal Test Kepribadian 
Setelah siswa mengisi soal test kepribadian, diakhir sistem siswa akan diperlihatkan tampilah hasil klasifikasi seperti pada gambar 6. Dari hasil klasifikasi tersebut siswa akan diberikan penjelasan mengenai kepribadian tersebut dan cara belajar seperti apa yang dapat meningkatkan akademik siswa.

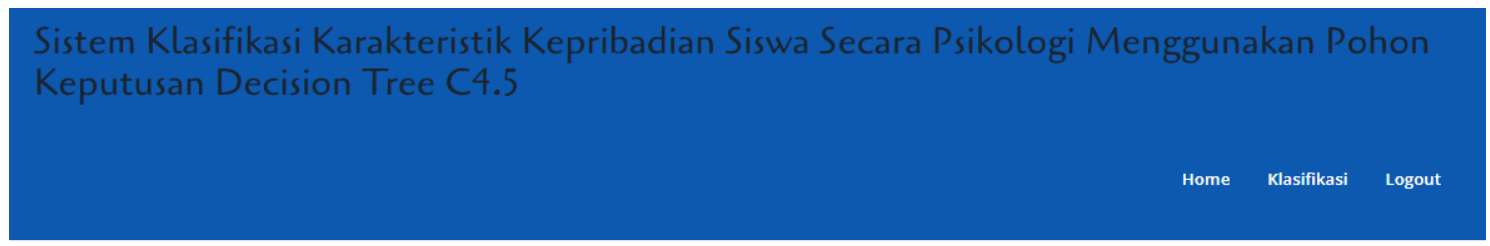

\title{
Test Kepribadian Secara Psikologi
}

\author{
Klasifikasi karakteristik kepribadian Anda: \\ Koleris
}

Gambar 6. Tampilan Hasil Test Kepribadian

Setelah model diimplementasikan selanjutnya adalah pengujian. Pengujian yang dilakukan adala untuk menguji ketepatan hasil klasifikasi dari metode yang digunakan. Pengujian dilakukan dengan menggunakan 20 sampel secara acak yang nantinya akan dibandingkan jawabannya dengan ahli. Tabel 1 berikut ini adalah hasil precision, recall dan accuracy.

Tabel 1. Hasil Uji Presisi, Recall dan Akurasi

\begin{tabular}{cccc}
\hline & Precision & Recall & Accuracy \\
\hline Hasil & 0.90 & 0.85 & 0.88 \\
\hline
\end{tabular}

Berdasarkan Tabel 1 menunjukkan bahwa nilai precision adalah 0,90 atau 90\%. Ini artinya tingkat ketepatan informasi yang diberikan adalah $80 \%$. Sedangkan recall mendapat nilai 0,85 atau $85 \%$, ini artinya tingkat keberhasilan sistem dalam menemukan kembali informasi mencapai $88 \%$. Kemudian untuk akurasi mendapatkan nilai 0.88 atau $88 \%$, ini artinya tingkat kedekatan antara nilai prediksi dengan nilai aktual mencapai $88 \%$. Hasil pengujian akurasi tersebut dikonversi dengan kriteri berikut: Baik, dengan nilai 76\%-100\%; Cukup, dengan nilai 56\%-75\%; Kurang Baik, dengan nilai 40\%-55\%, sedangkan Kurang Baik, memiliki nilai kurang dari 40\% [27]. Maka akurasi yang dihasilkan termasuk dalam kategori baik. Hasil tersebut menunjukkan bahwa metode pohon keputusan C.45 dapat menghasilkan sistem dengan nilai klasifikasi yang baik

\section{KESIMPULAN}

Penelitian ini mengembangkan sistem klasifikasi tipe kepribadian siswa secara psikologi dengan menggunakan algoritma pohon keputusan C.45. Pada penelitian ini sistem dikembangkan berbasis web, sehingga mudah digunakan untuk guru dan siswa untuk mengenali kepribadian dari siswa tersebut. Untuk mengetahui kepribadian siswa secara psikologis, siswa menjawab soal di sistem, kemudian sistem akan mengklasifikasikan berdasarkan jawaban dari siswa tersebut. Algoritma pohon keputusan C.45 berfungsi untuk menemukan pengetahuan atau pola-pola kesamaan karakteristik dalam suatu kelompok atau kelas tertentu. Dari hasi pengunjian mendapatkan nilai pecision sebesar $90 \%$, recall sebesar $85 \%$ dan accuracy sebesar 88\%. Ini menunjukkan bahwa algoritma pohon keputusan C.45 dapat melakukan klasifikasi tipe kepribadian dengan baik. Akan tetapi ada beberapa perbaikan yang dapat dilakukan untuk penelitian kedepan, diantaranya: mengembangkan sistem berbasis Android dan menggunakan algoritma klasifikasi lainnya agar dapat membandingkan hasil efektifitas dari algoritma yang digunakan.

\section{REFERENCES}

[1] S. N. Rochmawati, I. Istiadi, F. Marisa, and F. Nurdiansyah, "Klasifikasi Potensi Berdasarkan Kepribadian Siswa Dengan Metode Naive Bayes," in Conference on Innovation and Application of Science and Technology (CIASTECH 2020), 2020, pp. 327-334.

[2] Z. Zumkasri and S. Hardianti, "Gambaran Tipe Kepribadian Siswa di SMP Negeri 01 Kabupaten Bengkulu Utara," J. Psikodidaktika, vol. 3, no. 2, pp. 42-49, 2018.

[3] J. Siswanta, "Pengembangan Karakter Kepribadian Anak Usia Dini (Studi Pada PAUD Islam Terpadu Di Kabupaten Magelang Tahun 2015)," INFERENSI J. Penelit. Sos. Keagamaan, vol. 11, no. 1, pp. 97-118, 2017.

[4] D. C. Saragih, H. D. Windarwati, and A. Merdikawati, "Apakah Tipe Kepribadian Berhubungan Dengan Kecenderungan Perilaku Cyberbullying pada Remaja?,” J. Keperawatan Jiwa, vol. 8, no. 3, pp. 307-318, 2020. 
[5] E. D. Sikumbang, "Penerapan Data Mining Penjualan Sepatu Menggunakan Metode Algoritma Apriori," J. Tek. Komput. AMIK BSI, vol. 4, no. 1, pp. 1-4, 2018.

[6] A. S. Febriarini and E. Z. Astuti, "Penerapan Algoritma C4.5 untuk Prediksi Kepuasan Penumpang Bus Rapid Transit (BRT) Trans Semarang," Eksplora Inform., vol. 8, no. 2, pp. 95-103, 2019.

[7] R. I. Borman and M. Wati, "Penerapan Data Maining Dalam Klasifikasi Data Anggota Kopdit Sejahtera Bandarlampung Dengan Algoritma Naïve Bayes," J. Ilm. Fak. Ilmu Komput., vol. 9, no. 1, pp. 25-34, 2020.

[8] P. Prasetyawan, I. Ahmad, R. I. Borman, A. Ardiansyah, Y. A. Pahlevi, and D. E. Kurniawan, "Classification of the Period Undergraduate Study Using Back-propagation Neural Network," in Proceedings of the 2018 International Conference on Applied Engineering, ICAE 2018, 2018.

[9] R. I. Borman, B. Priopradono, and A. R. Syah, "Klasifikasi Objek Kode Tangan pada Pengenalan Isyarat Alphabet Bahasa Isyarat Indonesia (Bisindo)," in Seminar Nasional Informatika dan Aplikasinya (SNIA), 2017, no. September, pp. 1-4.

[10] N. Azwanti, “Algoritma C4.5 Untuk Memprediksi Mahasiswa Yang Mengulang Mata Kuliah (Studi Kasus Di Amik Labuhan Batu)," Simetris J. Tek. Mesin, Elektro dan Ilmu Komput., vol. 9, no. 1, pp. 11-22, 2018.

[11] E. Elisa, "Analisa dan Penerapan Algoritma C4.5 Dalam Data Mining Untuk Mengidentifikasi Faktor-Faktor Penyebab Kecelakaan Kerja Kontruksi PT.Arupadhatu Adisesanti," J. Online Inform., vol. 2, no. 1, p. 36, 2017.

[12] J. P. Gultom and A. Rikki, "Implementasi Data Mining menggunakan Algoritma C-45 pada Data Masyarakat Kecamatan Garoga untuk Menentukan Pola Penerima Beras Raskin,” Kumpul. Artik. Karya Ilm. Fak. Ilmu Komput., vol. 02, no. 01, pp. 11-19, 2020.

[13] I. Handayani, "Penerapan Algortima C4.5 Untuk Klasifikasi Penyakit Disk Hernia dan Spondylolisthesis Dalam Kolumna Vertebralis," JASIEK, vol. 1, no. 2, pp. 83-88, 2019.

[14] E. Fitriani, R. Aryanti, A. Saepudin, and D. Ardiansyah, "Penerapan Algoritma C4.5 Untuk Klasifikasi Penempatan Tenaga Marketing," Paradig. -Jurnal Inform. dan Komput., vol. 22, no. 1, pp. 72-78, 2020.

[15] T. Taufiq and Y. Yudihartanti, "Penerapan Algoritma C4.5 Klasifikasi Tingkat Kelulusan Mahasiswa," in Seminar Nasional Ilmu Komputer (SOLITER), 2019, vol. 2, pp. 153-162.

[16] R. I. Borman, I. Yasin, M. A. P. Darma, I. Ahmad, Y. Fernando, and A. Ambarwari, "Pengembangan Dan Pendampingan Sistem Informasi Pengolahan Pendapatan Jasa Pada PT. DMS Konsultan Bandar Lampung,” J. Soc. Sci. Technol. Community Serv., vol. 1, no. 2, pp. 24-31, 2020.

[17] R. I. Borman, A. T. Priandika, and A. R. Edison, "Implementasi Metode Pengembangan Sistem Extreme Programming (XP) pada Aplikasi Investasi Peternakan,” JUSTIN (Jurnal Sist. dan Teknol. Informasi), vol. 8, no. 3, pp. 272-277, 2020.

[18] M. Melinda, R. I. Borman, and E. R. Susanto, "Rancang Bangun Sistem Informasi Publik Berbasis Web (Studi Kasus : Desa Durian Kecamatan Padang Cermin Kabupaten Pesawaran)," J. Tekno Kompak, vol. 11, no. 1, p. 1, 2018.

[19] A. D. Saputra and R. I. Borman, "Sistem Informasi Pelayanan Jasa Foto Berbasis Android (Studi Kasus: Ace Photography Way Kanan),” J. Teknol. dan Sist. Inf., vol. 1, no. 2, pp. 87-94, 2020.

[20] R. D. Gunawan, T. Oktavia, and R. I. Borman, "Perancangan Sistem Informasi Beasiswa Program Indonesia Pintar (PIP) Berbasis Online (Tudi Kasus : SMA N 1 Kota Bumi)," J. Mikrotik, vol. 8, no. 1, pp. 43-54, 2018.

[21] A. Z. Pratama, L. Kurniawati, S. Larbona, and T. Haryanti, "Algoritma C4.5 Untuk Klasifikasi Nasabah Dalam Memprediksi Kredit Macet," Inf. Syst. Educ. Provesionals, vol. 3, no. 2, pp. 121-130, 2019.

[22] P. B. N. Setio, D. R. S. Saputro, and B. Winarno, "Klasifikasi dengan Pohon Keputusan Berbasis Algoritme C4.5," in Prosiding Seminar Nasional Matematika (PRISMA), 2020, pp. 64-71.

[23] A. Asroni, B. M. Respati, and S. Riyadi, "Penerapan Algoritma C4.5 untuk Klasifikasi Jenis Pekerjaan Alumni di Universitas Muhammadiyah Yogyakarta," Semesta Tek., vol. 21, no. 2, pp. 158-165, 2018.

[24] Y. Handrianto and M. Farhan, "C.45 Algorithm for Classification of Causes of Landslides," J. Publ. Informatics Eng. Res., vol. 4, no. 1, pp. 120-127, 2019.

[25] I. Ahmad, R. I. Borman, J. Fakhrurozi, and G. G. Caksana, "Software Development Dengan Extreme Programming (XP) Pada Aplikasi Deteksi Kemiripan Judul Skripsi Berbasis Android,” J. Invotek Polbeng - Seri Inform., vol. 5, no. 2, pp. 297 307, 2020.

[26] M. F. Arifin and D. Fitrianah, "Penerapan Algoritma Klasifikasi C4.5 Dalam Rekomendasi Penerimaan Mitra Penjualan Studi Kasus: PT Atria Artha Persada," InComTech, vol. 8, no. 2, pp. 87-102, 2018.

[27] R. I. Borman, R. Napianto, P. Nurlandari, and Z. Abidin, "Implementasi Certainty Factor Dalam Mengatasi Ketidakpastian Pada Sistem Pakar Diagnosa Penyakit Kuda Laut,” JURTEKSI (Jurnal Teknol. dan Sist. Informasi), vol. VII, no. 1, pp. 1-8, 2020 . 